Preprint. Paper published in 2015 in Land Economics 91(2):252-271

\title{
Restoring native vegetation in an agricultural landscape: spatial optimization for woodland birds
}

Maksym Polyakov, David J. Pannell, Morteza Chalak, Geoff Park, Anna Roberts, and Alexei D. Rowles

The authors are, respectively, research assistant professor, Centre for Environmental

Economics and Policy, University of Western Australia, Crawley, Western Australia,

Australia; Winthrop Professor and director, Centre for Environmental Economics and Policy,

University of Western Australia, Crawley, Western Australia, Australia; research assistant

professor, Centre for Environmental Economics and Policy, University of Western Australia,

Crawley, Western Australia, Australia; director, Natural Decisions Pty Ltd, Victoria,

Australia; director, Natural Decisions Pty Ltd, Victoria, Australia; and lecturer, Department of

Environmental Management and Ecology, La Trobe University, Wodonga, Victoria,

Australia. 


\title{
Restoring native vegetation in an agricultural landscape: spatial optimization for woodland birds
}

\begin{abstract}
In heavily cleared agricultural landscapes, decline of biodiversity could be prevented by restoring native habitat. In this paper, we develop a spatially explicit bioeconomic model that optimizes ecological restoration of habitat for woodland-dependent birds in the Australian state of Victoria. Spatial optimization identifies strategies that would generate substantially greater environmental benefits than is likely to be achieved in current programs. Greater biodiversity outcomes can be expected where restoration is optimized across multiple species rather than just individual species, and if the program does not require an even distribution of restoration effort amongst farmers.
\end{abstract}

Keywords: ecological restoration, biodiversity, habitat, spatial optimization, nonlinear programming

JEL Classification: Q57, R14 


\section{Introduction}

Australia's biodiversity continues to be threatened by losses of native vegetation (Australian State of the Environment Committee 2006), especially in regions of intensive agricultural production. Since European settlement, one third of Australia's woodlands, including $80 \%$ of southern temperate woodlands, have been cleared (Olsen et al. 2005). In many agricultural areas the remaining native vegetation is highly fragmented. In these areas, traditional conservation strategies based on protection of intact landscapes as large individual reserves are difficult to apply (Moilanen et al. 2005). Further decline of biodiversity could be prevented and perhaps reversed by restoring native vegetation and rebuilding functioning landscapes (Thomson et al. 2009). The importance of landscape restoration is recognised in Australia's Biodiversity Conservation Strategy (Australian National Biodiversity Strategy Review Task Group 2010). Specifically, it states that by 2015, 100,000 hectares (ha) (247105 acres) of fragmented landscapes and aquatic systems should be restored to improve ecological connectivity.

This study is motivated by the need to support decision making by environmental managers and policy makers in Australia who are responsible for meeting or contributing to this restoration target. Their decision making task is challenging for a range of reasons. Firstly, in highly fragmented landscapes, spatial context determines the benefits of landscape restoration (Lindenmayer et al. 2002; McBride et al. 2010). The benefits depend in large part on the extent and spatial pattern of existing vegetation (to which restored areas will be added) because the characteristics of existing vegetation affect the capability of restored vegetation to support biodiversity (Bennett et al. 2006; Manning et al. 2006; Thomson et al. 2009). Secondly, ecological restoration in an agricultural landscape (Polasky et al. 2005) faces high restoration costs and high opportunity costs due to loss of productive land. The public funding available to support restoration is modest, so high-quality prioritization of effort is required. 
Thirdly, the outcome of ecological restoration depends on a number of factors, including site selection, cooperation of landowners (where restoration is planned on private lands) (McBride et al. 2010) and predictions of species distributions. The latter requires detailed information that often is not available for many of the target species.

In this paper we report on research that aims to meet these challenges. Through engagement with managers, we observed that existing decisions about restoration investments are often not based on economically sound analytical evidence. We describe a spatially explicit bio-economic optimization model that maximizes biodiversity outcomes on a catchment scale subject to budget constraints and accounting for opportunity costs, including loss of agricultural production. The biodiversity outcome in this study is to maximize the predicted probability of occurrence of 28 species of woodland-dependent birds (Westphal et al. 2007). Woodland-dependent birds are sensitive to habitat changes at both the site level (Seavy and Alexander 2011) and the landscape level (Radford and Bennett 2007; Haslem and Bennett 2008). We use high-resolution spatial data to identify existing vegetation, including scattered, roadside and streamside woody vegetation, which are small but important elements of habitat in agricultural landscapes in the study region. We develop a nonlinear programming model, using detailed biological response functions derived from extensive field studies. A novel feature, relative to existing studies, is that the model allows partial, rather than full, ecological restoration within each represented spatial unit, as explained later.

There exists a large literature on systematic conservation planning (e.g., Margules and Pressey 2000; Cabeza et al. 2004; Moilanen et al. 2005). Prioritization of ecological restoration in agricultural landscapes forms a small sub-set of this literature (McBride et al. 2010). Within the larger literature, there is a tendency for economics to be neglected. For example, in their survey of protected area planning literature, Newburn et al. (2005) found that only $13 \%$ of studies discussed the economic cost of conserving habitat, even though it has 
repeatedly been recognised as a critical element (Ando et al. 1998; Polasky et al. 2005;

Naidoo et al. 2006; Wilson et al. 2007; Wilson et al. 2009). Existing restoration prioritization studies also optimize to a constraint on area of restoration (e.g., Thomson et al. 2009), rather than a budget.

In this paper we describe a spatially explicit bio-economic optimization model that maximizes certain biodiversity outcomes on a catchment scale subject to budget constraints and accounting for opportunity costs, including loss of agricultural production. We use highresolution spatial data to identify existing vegetation, including scattered, roadside and streamside woody vegetation. These are small but important elements of habitat in agricultural landscapes in the study region. We develop a nonlinear programming model, using detailed biological response functions. A novel feature, relative to existing studies, is that the model allows partial ecological restoration of each represented spatial unit, as explained later.

Aims of the study are three-fold; (i) to identify optimal locations and spatial arrangements of habitat restoration efforts for a case-study region: the Avoca catchment, an area of 330,000 hectares $(820,000$ acres $)$ in the Australian state of Victoria. Optimization can be subjected to constraints on the available program budget or on the target level of biodiversity. (ii) To quantify the gain in biodiversity outcomes when landscape restoration is optimized subject to a constraint on financial resources instead of on area. (iii) To quantify the loss in biodiversity outcomes if restoration is constrained to occur over an equal share of every sub-region or every farm. This scenario approximately simulates the strategy of some past Australian Government programs. 


\section{Materials and Methods}

\section{Study site and partitioning the landscape}

The study site is the upper Avoca river catchment in North Central Victoria (Figure 1). The region has a Mediterranean climate, with hot dry summers, cool wet winters, and most rainfall being received in winter and spring. Average rainfall varies from $400 \mathrm{~mm} / \mathrm{year}$ in the north to $700 \mathrm{~mm} /$ year in the south. The elevation ranges between $100 \mathrm{~m}$ in the north and 350 $\mathrm{m}$ in the south of the catchment. The pattern of native vegetation of the study region has been significantly modified by mining and agriculture since European settlement. Currently, only about $25 \%$ of 330,000 ha is covered by native vegetation and other woodlands. The dominant native vegetation types are Box Ironbark Forest, Grassy Woodlands, and Grassy Dry Forest (DSE 2007) in a matrix of native pastures, modified pastures, crops, and vineyards. The North Central Catchment Management Authority, which manages natural resources in the region, has an aspirational target of increasing the extent of native vegetation to 30 percent of the region (North Central Catchment Management Authority 2005). This is based on previous indications that major ecological change occurs when habitat cover declines below 10-30\% of the landscape (Andren 1994).

[Insert Figure 1 about here]

Because land use and spatial patterns of land cover affect both biodiversity and production outcomes, it is important to design a representation of the landscape that suits both the modeling for achieving biodiversity outcomes and the optimization of restoration patterns. A traditional approach to spatially explicit modeling of landscape restoration is to partition each planning region into a set of distinct homogenous spatial units which could be either regular, such as squares (Polasky et al. 2001; Westphal et al. 2007), or irregular, such as fields or property parcels (Polasky et al. 2008), and to treat inclusion of these spatial units in the optimization problem as binary variables. However, for highly fragmented landscapes, the 
use of homogenous spatial units of a relatively large size, e.g., $250 \times 250 \mathrm{~m}$ or 6.25 ha, (Westphal et al. 2007; Thomson et al. 2009) leads to the loss of information about small remnants, such as stand-alone trees in agricultural fields, and roadside or creek-line vegetation. When the spatial units are small enough to represent small remnants, e.g., $25 \times 25$ $\mathrm{m}$ or $0.0625 \mathrm{ha}$, the optimization problem becomes computationally difficult or infeasible. On the other hand, using irregular spatial units that represent properties or fields and treating the optimization problem as integer or binary implies that whole management units will undergo ecological restoration (for example when a whole property is purchased). In reality, it is more common for ecological restoration on private lands to occur on only fractions of a field. This is explained by increasing marginal opportunity cost of ecological restoration on individual properties due to diminishing marginal values of both agricultural land and native vegetation (Polyakov et al. 2014). As a result, the willingness of landholders to participate in conservation programs is higher when only a small proportion of the property is required for conservation management (Adams et al. 2014).

To address these issues we partition the landscape into larger regular cells, each of which consists of a number of homogenous spatial units. The planning region, with a 2 kilometers $(\mathrm{km})$ (1.25 miles) buffer to minimize edge effects, is partitioned by overlaying a regular grid consisting of 5957 hexagonal cells with side length of $500 \mathrm{~m}$ and area of approximately 65 ha. A hexagon with its second and third order neighbors approximates a 2 $\mathrm{km}$ radius circle. This size was chosen to keep the problem computationally tractable and to match the design of species distribution models where the probability of occurrence is determined by landscape characteristics within $2 \mathrm{~km}$ (Polyakov et al. 2013b). Each hexagonal cell $n$ is divided into homogenous spatial units of varying size by overlaying spatial layers of property parcels, land uses, landforms (Rees and Rowan 2000), vegetation density types ('dense', 'scattered', and 'open'), and groups of pre-clearance Ecological Vegetation Classes 
(EVCs) (DSE 2007). Each modeling unit is identified by ID of the hexagon $n$, ID of the property $m$, landform $f$, land use $l$, vegetation density type $d$, and EVC group $e$. This resulted in 141,387 spatial units, of which 28,685 spatial units are on agricultural lands not covered by woody vegetation and are considered for ecological restoration. We assume that native vegetation could be restored on any fraction of a spatial unit. These spatial units are the decision unit for the model. The purpose of defining regular hexagons is to represent the spatial context of the landscape. All spatial units within a hexagon are assumed to have the same relative location in the optimization model. This allows an adequate representation of habitat mix within each hexagon and reduces computational effort. However, the fine-scale spatial pattern of habitat within each hexagon is ignored.

\section{Biological model}

To predict the probability of occurrence of 28 woodland-dependent bird species in woodlands across the landscape, we use the biological model developed by Polyakov et al. (2013b) based on the data collected by J. Radford (Radford et al. 2005; Radford and Bennett 2007). The probability of occurrence of a species on a 2 ha patch of suitable habitat is determined by the characteristics of the landscape, such as proportions of the groups of ecological vegetation classes and densities of the woodlands within $2 \mathrm{~km}$ of the patch. Four types of native vegetation (for bird habitat) are included (Table 1, Figure 2).

[Insert Table 1 about here]

[Insert Figure 2 about here]

The probabilities of occurrence of individual species change depending on the species' response to habitat area and habitat type in a landscape context, as represented in the biological model. Landscape characteristics with a closer proximity to the patch of habitat are assumed to have a greater effect on probability of occurrence than are the characteristics of more distant landscapes. In the models developed by Polyakov et al. (2013b) this is 
represented by weighting characteristics of the surrounding landscape where the weights are proportional to the inverse of squared distance. Inverse squared distance weight was selected because, based on AIC statistic, it performed better than inverse distance weights in models of probability of occurrence for all species.

To calculate the biodiversity score of each species, we use summed probability of occurrence (SPO) for each of the 28 woodland-dependent bird species $s$. SPO is the product of habitat area and probability of occurrence summed over the landscape:

$$
S P O_{s}=\sum_{N}\left(p_{s n}\left(\mathbf{W}_{n} \mathbf{A} \boldsymbol{\beta}_{s}\right) \times \sum_{E} a_{n e} / 2\right)
$$

where $p_{s n}$ is the probability that species $s$ occurs on every 2 ha of habitat (woodlands) within hexagon $n$ and $a_{n e}$ is the area of habitat type $e$ within hexagon $n . a_{n e}$ is divided by 2 to represents number of 2 ha patches of habitat within hexagon $n . N$ is the total number of hexagons in the landscape, and $E$ is the total number of vegetation types. W is the $N \times N$ matrix of weights, which are proportional to inverse square distances between hexagon $n$ and hexagons located within $2 \mathrm{~km}$, and $\mathbf{W}_{n}$ is $n$-th row of $\mathbf{W}$ representing vector of weights specific to hexagon $n$. A is the $N \times E$ matrix of the areas $\left(a_{n e}\right)$ of woodland vegetation types or their combinations within a hexagons. Vegetation located within nearer hexagons is given higher weights as its impact on SPO is larger. $\mathbf{W}_{n} \mathbf{A}$ is the vector of weighted areas of vegetation types or their combinations within $2 \mathrm{~km}$ of hexagon $n$. $\boldsymbol{\beta}_{s}$ is the $1 \times E$ vector of parameters of a logistic regression of probability of occurrence of species $s$. Probability $p_{s n}(\cdot)$ is a logistic function: $p_{s n}\left(\mathbf{W}_{n} \mathbf{A} \boldsymbol{\beta}_{s}\right)=1 /\left(1+\exp \left(-\mathbf{W}_{n} \mathbf{A} \boldsymbol{\beta}_{s}\right)\right)$; this represents the relationship between the characteristics of the surrounding landscape and the occurrence of this species. The area of habitat type $e$ in hexagon $n\left(a_{n e}\right)$ consists of the area of existing vegetation and the area of restored vegetation: 


$$
a_{n e}=\sum_{L} \sum_{M} \sum_{F} x_{n e l m f}+\sum_{L} \sum_{M} \sum_{F} y_{n e l m f}
$$

where $x_{\text {nelmf }}$ represents existing vegetation and $y_{\text {nelmf }}$ represents the restored area of vegetation type $e$ in hexagon $n$, land use $l$, farm $m$, and landform $f . L$ is the number of land uses, $M$ is number of properties (farms), and $F$ is the number of landforms.

Restoration of $y_{\text {nelmf }}$ hectares of native vegetation has two effects on the aggregate SPO: 1 ) a direct effect by increasing $a_{n e}$ (the area of available habitat) and, 2) an indirect effect by increasing probability of occurrence through $\mathbf{W}_{n} \mathbf{A}$ (equation 1) on existing habitat within $2 \mathrm{~km}$ of the restored site. While habitat agglomeration and reduction of fragmentation are well accepted targets in the science and practice of ecological restoration (Parkhurst et al. 2002; Lewis et al. 2009), the indirect effect that restored habitat has on the neighboring existing habitat has not previously been explicitly taken into account when optimizing ecological restoration.

We note that if suitable data were available, it would be possible to adapt this model to wildlife other than birds. A model of response to restoration is needed for any attempt to optimize or evaluate ecological restoration efforts.

\section{Optimization model}

The model optimally allocates ecological restoration across the landscape by maximizing a measure of biodiversity (SPO) subject to a constraint, such as area or economic cost. Most previous studies optimizing landscape restoration have used integer programming (Polasky et al. 2005; Crossman and Bryan 2006) or simulated annealing (Westphal et al. 2007; Watts et al. 2009). However, to allow for partial ecological restoration of the spatial units we apply nonlinear programming. Previous research has shown that approximating continuous solutions with discrete solutions can lead to inefficiencies (Peck and Adams 2010). 
We optimize landscape restoration by maximizing a measure of biodiversity as the objective function (3). We solve the optimization problem subject to availability of land for restoration (3a) and a set of budget constraints, which are either restored area or economic $\operatorname{cost}(3 b)$ :

$$
\begin{array}{ll}
\text { Maximize } & \sum_{S} F_{s}\left(S P O_{s}\right) \\
\text { subject to } & 0 \leq y_{\text {nelmf }} \leq y_{\text {nelmf }}^{\max } \forall n, e, l, m, f \\
& \sum_{N} \sum_{E} \sum_{L} \sum_{M} y_{\text {nelmf }} \times\left(c_{l}+o_{f}+f\left(y_{\text {nelmf }}\right)\right)<B
\end{array}
$$

where $F_{s}$ is the value function for SPO; $y_{\text {nelmf }}^{\max }$ is the area available for ecological restoration within each hexagon $n$, farm $m$, land use $l$, vegetation type $e$, and landform $f ; c_{l}$ is the restoration and management cost; $o_{l}$ is the opportunity cost of agricultural production per hectare in land use $l ; f\left(y_{\text {nelmf }}\right)$ is the fencing cost as a function of the area of restoration project; and $B$ is the budget constraint. When restoration and fencing costs are ignored, the budget constraint becomes an area constraint:

$$
\sum_{N} \sum_{E} \sum_{L} \sum_{M} y_{n e l m f}<Y
$$

where $Y$ is the area constraint. This enables us to assess the advantages and disadvantages of using area or economic cost in optimizing landscape restoration.

Some studies have adopted an objective of maximizing aggregate species abundance, but this may disadvantage species with low initial levels of abundance and species with low responsiveness to conservation action (Westphal et al. 2007). One of the approaches to address this issue is to construct an aggregate measure of biodiversity outcome by applying weights that reflect the level of threat to the species and/or the current abundance/occurrence of each species. 
Westphal et al. (2007) apply lower weights to species with either high or low levels of response to ecological restoration. The reason for applying low weights to high levels of response is to provide additional advantage to less-abundant species. The rationale for reduced weighting of species that have a low response to ecological restoration is to prevent selection of a reserve which cannot support a viable population. However, in planning ecological restoration in an agricultural landscape, even a small increase in less-abundant species may be considered valuable. Arponen et al. (2005) describe a set of weighting functions that allows reduced weights for species with above-target populations and account for the levels of threat to individual species. In this study we use two different value functions $\left(F_{s}\right)$. In the first vale function, no weights are applied to different species, $F_{s}\left(S P O_{s}\right)=S P O_{s}$. The weakness of this approach is that the model maximized aggregate SPO irrespective of whether species are rare or abundant. In the second value function, the value of each species is weighted depending on its abundance as shown in equation (4). In this function, value increases with SPO, but has a negative first derivative and approaches an asymptote at a high level of SPO:

$$
F_{s}\left(S P O_{s}\right)=r^{-1}\left(1-\exp \left(-\gamma S P O_{s}\right)\right)
$$

where parameter $r$ is the inverse of the species value at high abundance, and parameter $\gamma$ is determined so that $F_{s}\left(T_{s}\right)=1$ for a given $r$, where $T_{s}$ is the target abundance of species $s$ (Arponen et al. 2005). We assume target abundance $\left(T_{s}\right)$ is the SPO that could be achieved when the landscape is reconstructed to maximize abundance of this species subject to the area of ecological restoration equaling 16,000 ha. This is equivalent to a $20 \%$ increase in the current extent of native vegetation. As native vegetation cover in the region is currently $25 \%$, a $20 \%$ increase in this area would achieve the North Central CMA's aspirational target of $30 \%$ native vegetation cover. Because the set of species modeled did not include any that are listed as endangered (red-book-listed), we used the same value of $r$ for all species (0.9). 
However, equation (4) still results in different weights for each species depending on its current abundance relative to its maximum potential abundance (following 16,000 ha of ecological restoration). The advantage of the second value function is the possibility to account for diminishing returns to ecological restoration in more abundant species. However, the weights are set relative to somewhat arbitrary levels of target abundances.

The costs are the capitalized loss of agricultural production due to ecological restoration plus the input cost of ecological restoration and management, including cost of exclusion (fencing). We assume that the capitalized loss of agricultural production is equal to per-hectare land values on large agricultural properties (Lee and Thompson 2005). In the Avoca catchment, the sale price of pasture land is assumed to be $\$ 990 /$ ha and the sale price of land suitable for mixed cropping is $\$ 1730 /$ ha (L. Ezard, pers. comm.). (The currency used is Australian dollars throughout. In November 2013, US\$1.00 = AU\$1.06.) According to the land-use maps of the catchment, mixed cropping enterprises are located in the lower (flat, plain) parts of the landscape, while grazing-only lands are located in the hilly parts of the landscape. We use the 'Landforms' attribute from the LSYS250 GIS dataset (Rees and Rowan 2000) to assign opportunity costs to agricultural lands suitable for ecological restoration. There is substantial spatial heterogeneity in landform across the landscape (Figure 2). Furthermore, we assume that land within certain land uses, such as 'natural feature protection', is not used for agricultural production and therefore ecological restoration of such land does not involve opportunity cost and only includes restoration and management costs. These three levels of opportunity costs are representative of the range of returns to actual production; however, they are less heterogeneous than in reality. There is also additional spatial heterogeneity in costs represented in the model due to variation in the cost of establishing native vegetation on different current land uses. 
The input cost of ecological restoration and management is calculated using a combination of possible management actions (planting with tube stock or direct seeding, fencing of restored sites, as well as follow-up weed management) depending on the current land use. Standard prices used by the North Central Catchment Management Authority (CMA) are applied when costing on-ground works. We assume that croplands and modified pastures would be re-vegetated using a combination of tube stock (bare paddock: 400 trees/shrubs per ha at $\$ 2,880 /$ ha $)$ and direct seeding $(\$ 1,440 /$ ha $)$, followed by non-woody weed management (spraying: $\$ 1,000 /$ ha). Areas with land uses such as 'grazing natural vegetation' and nature protection would be re-vegetated using direct seeding at \$1,440/ha. In all cases we assume that each re-vegetated area will be fenced at the cost of $\$ 7,000 / \mathrm{km}$. We assume separate 'restoration projects' for each farm and land use within each hexagon.

We need information about the perimeter length of restoration projects because this determines the cost of fencing. We calculate areas and perimeters of polygons of individual land uses from GIS data for the Avoca catchment. We then develop a regression model to estimate perimeter length as a function of patch area, separately for land-use classes. (Natural vegetation will have longer perimeters per hectare due to less regular shapes, relative to cropping, for example.) The regression model is needed because the perimeter lengths of restoration projects cannot be known in advance and need to be calculated endogenously.

In addition to the base-case scenario, which is a spatially targeted strategy, we examine two ecological restoration scenarios with constraints that require the proportion of restoration within certain spatial units to be equal. In one of these scenarios, the model is constrained to include an equal proportion of ecological restoration that is within each of five local government areas (LGAs) in the study zone, while another scenario requires that proportions of ecological restoration be equal for each farm. These scenarios represent relatively untargeted ecological restoration strategies, although restoration is still targeted 
within each LGA or within each farm. This reflects practices in past Australian Government Programs, such as the Natural Heritage Trust, which put an emphasis on sharing program funds "equitably" between regions and between farms.

\section{Results and Discussion}

Funding for biodiversity protection is often allocated on a species-by-species basis. For example, the Victorian Investment Framework for Natural Resource Management states that on-the-ground actions that address threatening processes for a specific threatened species are considered a funding priority (DSE 2012). Such species-specific targeting could be at the expense of broader ecological communities. We assess this potential tradeoff by observing the reduction in the aggregate summed probability of occurrence (SPO) of all 28 bird species when ecological restoration is instead optimized for a particular species rather than for the entire group. To achieve this, we first maximize the aggregate SPO of all 28 species together and the individual SPO of each bird species separately by optimizing ecological restoration using an area constraint of 16,000 ha, equivalent to a $20 \%$ increase in the current extent of native vegetation. Optimizing extent and composition of ecological restoration for each of the species individually provides insight into both the variation in the individual species response and the details of their specific habitat preferences, which helps when interpreting aggregate results.

Figure 3 shows the potential increase in SPO for each bird species when optimized individually. The figure uses base-2 logarithmic scales for both axes with diagonal lines showing $20 \%$ and $100 \%$ SPO improvement. Results show that there is a large variation in both initial SPO levels and responses to optimal ecological restoration.

[Insert Figure 3 about here] 
There is a variation in the extent and composition of restored vegetation optimal for individual species. To illustrate this, we solve the model minimizing restored area to achieve a $20 \%$ increase separately for each species. Figure 4 shows the area required for each species to achieve the target, broken down by vegetation types. The species on the figure are arranged from least abundant on the left to most abundant on the right. The area required to achieve a $20 \%$ improvement of SPO varies from 480 ha for the Peaceful Dove to 13,430 ha for Red Wattlebird with median value around 6700 ha (Figure 4). The majority of species prefer a combination of dry infertile and fertile grassy woodlands. These woodland habitats are typically dominant in the region and many bird species rely on both habitat types for feeding and breeding. However, a number of species, both with low and high abundance, prefer riparian vegetation and a small number, all with high abundance, prefer plain woodlands (Figure 4).

\section{[Insert Figure 4 about here]}

Although planning for conservation of threatened species is often conducted on the basis of individual species, results show that there is a trade-off between targeting individual species and groups of species. Optimizing ecological restoration for each of the species individually leads to a reduction in the aggregate SPO relative to its maximum potential (Table 2), ranging from a 1.8\% reduction (Spotted Pardalote) to an estimated $23.4 \%$ reduction (Red Wattlebird). What is optimal for one species may involve habitat area and vegetation composition that is inadequate for a suite of species in the wider bird community.

To illustrate, three of the species included in our study, Black-chinned Honeyeater, Brown Treecreeper and Diamond Firetail are classified as Near Threatened in Victoria (DSE 2013) and each has quite distinct preferences in terms of habitat characteristics. How well these align with habitat requirements beneficial to the entire species group has implications for the aggregate SPO. Specifically, Black-chinned Honeyeaters, requiring a combination of 
fertile grassy and dry infertile woodlands, appear to be a good surrogate for the majority of species (Figure 4). In contrast, the Brown Treecreeper and Diamond Firetail both have markedly different requirements for ecological restoration compared with most species assessed (Figure 4). Clearly, restoration optimized for either of these species individually will fail to cover requirements for the majority of species, resulting in the aggregate SPO which is $8.4 \%$ lower (Brown Treecreeper) or $15.5 \%$ lower (Diamond Firetail) than the aggregate SPO optimized for the set of species (Table 2). This highlights that single species-based conservation efforts can come at an opportunity cost to the wider bird community. Comparison of the Black-chinned honeyeater and Diamond Firetail suggests that the tradeoff from taking a single species approach is likely to be greater when optimizing ecological restoration for more specialized species likely to have a narrower range of habitat preferences. It appears counter-productive and less ecologically sound to maximize benefits for single species that may remain under pressure from other threats, particularly when it is to the detriment of the many. These results suggest that using a surrogate-species approach to targeting conservation efforts may pose a risk to the success of conservation efforts. Surrogate species need to be chosen very carefully or else conservation actions may be systematically biased against species not well represented by the surrogate.

[Insert Table 2 about here]

A compromise between optimizing for individual species and optimizing for a group of species could be achieved by scaling the SPO of individual species to benefit species that are perceived as more threatened. We model optimal ecological restoration of 16,000 ha in the study area. As noted earlier, we maximize two versions of the objective function: (a) the unweighted sum of SPOs across all species, and (b) the weighted sum of SPOs across all species, with weights determined by the value function (4). The value function for (b) was 
parameterized separately for each species, resulting in more weight being given to lessabundant species.

Results for the two objective functions are shown in Figure 5. The graph shows the increase in SPO for each species as a result of the maximization of aggregate SPO and maximization of aggregate weighted SPO. Whichever of the two objective functions is used, all of the bird species are increased in abundance as a result of the optimal restoration. As with the individual-species optimizations (Figure 3), there is considerable variation between species, with the increase in SPO ranging from less than 300 (Varied Sittella) to more than 7000 (Brown Treecreeper). Percentage increases (not graphed) ranged from 21\% (Red Wattlebird) to $150 \%$ (Peaceful Dove). Notably, results were very similar for the two objective functions: weighting species made little difference to the results. There is only a very slight tendency for weighting to reduce the gains made by already-abundant species (e.g., Red Wattlebird) and increase the gains for less-abundant species (e.g., Varied Sittella and Yellow Thornbill).

[Insert Figure 5 about here]

In some previous studies, ecological restoration has been optimized using an area constraint rather than a budget constraint (e.g., Crossman and Bryan 2006; Thomson et al. 2009). Here we explore what difference this makes to the environmental improvements that are achievable for a given budget. We first maximize aggregate SPO over a range of area constraints equal to $1,2,4,8$, and 16 thousand ha and calculate the economic cost of restoration for each ecological restoration area (Table 3). Costs range from A\$6.7 million to $\$ 88.0$ million (Table 3, third column). Next we use these costs as budget constraints to optimize the restoration pattern in the catchment (Table 3, first column). We present both direct and indirect effects of the ecological restoration on the improvement of biodiversity outcome. The direct effect is the increase of SPO due to an increase in the restored habitat. 
The indirect effect is the increase in SPO on existing native vegetation due to changes of the proportion and composition of habitat in the surrounding landscape. The proportion of the SPO increase that is due to the direct effect ranges from approximately $50 \%$ for the lowest budget to over $70 \%$ for the highest budget.

[Insert Table 3 about here]

Of key interest is the increase in bird abundance where budget rather than area is the constraint on ecological restoration. Table 4 shows that, at all area/budget levels, aggregate SPO improves as a result of using a budget rather than an area constraint. Under a budget constraint, the pattern of restoration shifts towards replacing land uses with lower opportunity costs, such as grazing. Nevertheless, in our study there remains substantial overlap between the two sets of solutions, ranging from 76 to $95 \%$ in common, depending on the area/budget level. As a result, the gain in environmental values resulting from a switch to the theoretically preferred budget constraint is modest ( $10 \%$ for the smallest budget) to small ( $2 \%$ for the largest budget). There are several reasons for this modest increase in biodiversity outcome. First, this is a small scale (catchment-level) study in a landscape dominated by agricultural production, which is more homogenous than national scale case studies (Ando et al. 1998). Greater heterogeneity, which we would expect at larger scales, would provide greater opportunity for selectivity, and therefore larger gains. Second, we assume that ecological restoration is conducted on private land with landowners compensated for the loss of agricultural production rather than by purchasing whole properties. The values of land for agricultural production in an extensive agricultural context do not vary as much as they would in a peri-urban landscape (Westphal et al. 2007) or if rural residential land use was also considered. In landscapes with more heterogeneous land uses than in the Avoca catchment, we would expect the use of a budget constraint to be more important than in our study. Third, one of the drivers of optimal restoration patterns in the model is the proximity to larger blocks 
of remnant vegetation, which are usually located in the parts of the landscape with less fertile and therefore less expensive soils. The costs are negatively correlated with environmental benefits, so cost targeting does not offer substantial gains over benefit targeting (Babcock et al. 1997; Wu et al. 2001). On the other hand, properties in these locations are more fragmented and smaller in size, often resulting in higher per-hectare prices. If we assumed that whole properties have to be purchased for ecological restoration, the advantage of using a budget constraint rather than an area constraint would have been larger. Finally, this result could be an artifact of the simplified representation of opportunity cost in our study (no heterogeneity in opportunity costs within a given land use). Results in the reminder of the paper are based on a budget constraint.

[Insert Table 4 about here]

For all budget levels, ecological restoration is concentrated in certain parts of the catchment where it can generate the largest environmental benefits (Figure 6). Specifically, it is mainly concentrated near existing large patches of native vegetation, consistent with findings of earlier studies (Westphal et al. 2007; Thomson et al. 2009). As the budget level increases, large patches of native vegetation grow accordingly.

[Insert Figure 6 about here]

Less obvious from Figure 6 is that some of the ecological restoration is targeted to riparian areas, especially riparian areas close to existing patches, benefiting species that prefer such vegetation types. For example, near the lower left corner of the more detailed map, there is visible a long thin strip of restored riparian vegetation under the lowest budget level (with the darkest shading). The current extent of riparian vegetation in the catchment is low, so new riparian vegetation is potentially highly valuable to reliant bird species.

Another result is that it is optimal for some restoration to be located near smaller sized patches. This increases the heterogeneity of the vegetation types, making the landscape more 
suitable for multiple bird species and thus contributing to high benefits from restoring riparian habitat.

The final set of results relates to the costs of constraining the spatial distribution of ecological restoration. Government programs for environmental restoration sometimes give weight to political objectives at the expense of environmental outcomes (as noted, for example, by Claassen et al. 2008). In Australia, programs such as the Natural Heritage Trust and the National Action Plan for Salinity and Water Quality were criticised for giving priority to allocating funds broadly amongst many participating landholders, rather than basing the allocation on achievement of the greatest possible environmental benefits (Pannell and Roberts 2010; Morrison et al. 2011). In these programs, environmental managers gave increased priority to a notion of "equity", interpreted as meaning a more equal distribution of funds between sub-regions and/or between farmers. Here we investigate the cost of this approach in terms of environmental benefits foregone.

To address this, we optimized ecological restoration of Avoca catchment subject to one of two additional constraints. One constrained the percentages of restored area to be equal in each of five Local Government Areas (LGA) in the catchment, while the other required equality of the percentages of restored area on every farm. Biodiversity outcomes (Table 5) and spatial patterns of ecological restoration (Figure 7) are presented for optimization results with and without these additional constraints. With the constraint applied at the farm level, 98 percent of selected spatial units received partial restoration. This demonstrates the benefit of using nonlinear programming as such outcome would not be possible with integer programming.

[Insert Table 6 about here]

[Insert Figure 7 about here] 
Comparing the first two panels of Figure 7, the LGA constraint results in a redistribution of the ecological restoration away from the western/southern LGAs towards the eastern/northern LGAs. New vegetation is still predominantly located close to existing vegetation, or in new large patches, but the changes in physical location are substantial. This is particularly true of the northern-most LGA, which has almost no ecological restoration in the absence of the LGA constraint. Despite the extent of change in spatial locations, the negative effect of the constraint in the objective function is very minor: in the order of a $1 \%$ reduction. The percentage impact does not vary greatly for different budget levels. The opportunities for environmentally beneficial ecological restoration in the newly favored LGAs are almost as good as the opportunities being foregone in the western and southern LGAs. There are still patches of vegetation that can be built on (in the eastern LGA) or opportunities for large new patches (in the northern LGA). If the politics require an equal allocation of environmental expenditures in different LGAs, this can be achieved at little environmental cost, at least in this case study. Another implication is that the optimization for ecological restoration in our study area could be done independently for each LGA with little loss of environmental values. These results indicate that some, or even most, of the losses resulting from the imposition of a political constraint such as this can be avoided by applying the constraint at a more aggregated level. In this case, the LGA level is large enough for optimization within each sub-region to produce good results, whereas the farm level clearly is not (see below). This insight may help planners to satisfy political preferences without greatly compromising environmental outcomes.

In contrast, a constraint that requires program funds to be allocated to all farmers in proportion to their farm area is environmentally very costly. Figure 7 shows that this results in a large number of very small patches of restored habitat across the catchment. Most new patches are isolated from existing native vegetation and from waterways. All are small 
relative to the optimal patch sizes illustrated in the first two panels. Not surprisingly, this constraint causes very large reductions in the potential gains from environmental restoration (Table 6). For the lowest budget level, which is broadly consistent with the level offered in previous programs, the reduction is around $80 \%$. Even for the highest budget level, there is a reduction of around $50 \%$. This is consistent with the findings of earlier studies that analyze the cost effectiveness of conservation in heterogeneous landscapes. For example, Rashford and Adams (2007) found that optimizing waterfowl production simultaneously over multiple small heterogeneous landscapes resulted in efficiency gains in comparison with optimizing for each landscape independently, due to synergetic effects.

Clearly, an essentially untargeted approach, as represented by the model with the farm constraint, is highly undesirable from an environmental perspective, resulting in missed opportunities for much more valuable environmental outcomes. On the other hand, a strategy that includes political constraints at a coarser scale, such as the LGA, can be almost as beneficial as the first-best strategy.

In this region, the main policy mechanism used to promote landscape restoration by private landholders (Stoneham et al. 2003) is the conservation tender. Conservation tenders or reverse auctions are used to procure conservation services on private lands. The results of this analysis could be used to adjust the metric used in the conservation tender process to decide on the allocation of resources among competing bids. However, even with such adjustments, the effectiveness of these programs is limited by the nature of the bids that are provided. A local environmental manager (one of the co-authors - Park) observed that the spatial pattern of conservation tender bids often varies significantly from the optimal spatial pattern identified by our model. Participants in these programs tend to be from the minority of landholders who are personally interested in conservation, whereas the optimal areas for restoration may be on land owned by people who are not conservation-oriented. Results of the 
study may be useful for targeting efforts to engage in the program landholders who have hitherto been uninterested.

Results highlight the high expense (relative to existing budgets) of achieving substantial environmental improvements. In the study region, the typical annual budget for conservation tenders over an area around four times the size of the Avoca catchment is $\$ 1$ to 2 million. Assuming that the Avoca catchment receives around $\$ 400,000$ per year, the present value of resources over 10 years would be $\$ 3.1$ million (5\% real discount rate). Clearly, the budgets assumed for this analysis ( $\$ 6.7$ million to $\$ 88$ million present value) are much larger than current actual budgets. We use higher budgets in order to be relevant to the CMA's target of 30 per cent vegetation. The model indicates that the maximum increase in aggregate SPO for a budget of $\$ 6.7$ million is $3.4 \%$. The observation that program budgets are much too small to achieve official targets reinforces findings of other Australian studies (e.g. Roberts $e t$ al. (2012) for water quality; Pannell and Roberts (2010) for soil salinity).

A limitation of this study is that it does not take into account private benefits (Pannell 2008) generated by native vegetation, such as amenity values (Polyakov et al. 2013a) or carbon payments (Ngugi et al. 2011). Including these values into the analysis would result in lower opportunity costs, and perhaps greater heterogeneity of opportunity costs, resulting in greater environmental outcomes for a given budget. The study could also be improved by including data on the heterogeneity of agricultural opportunity costs in the optimization model.

\section{Conclusion}

Inadequate attention has been given to the problem of how best to allocate scarce funding to environmental restoration activities in highly cleared agricultural landscapes to achieve the largest biodiversity benefits. In this study, conducted in the Avoca catchment in 
the Australian state of Victoria, we have found that incorporating improved spatial optimization considerations into conservation planning would substantially improve conservation outcomes.

The study makes a number of contributions to the literature. It adds to the very small number of existing studies on the spatial optimization of ecological restoration effort (Crossman and Bryan 2006; Westphal et al. 2007; Crossman and Bryan 2009; Thomson et al. 2009). It demonstrates an approach that recognizes internal heterogeneity of planning cells and allows partial restoration of cells, unlike previous studies. It employs non-linear programming to optimize, rather than heuristic approaches (Westphal et al. 2007; Thomson et al. 2009) or integer programming (Crossman and Bryan 2006, 2009). Unlike previous studies, it demonstrates that optimizing subject to an area constraint is not necessarily greatly inferior to using a budget constraint (cf. Ando et al. 1998), that constraining resource allocation to be shared 'equitably' between landholders can result in extremely large losses of environmental benefits, and that greater benefits can be achieved by optimizing for multiple species than for single-species outcomes. Single threatened species are currently the focus of government programs. While it is difficult to anticipate how widely applicable these findings are (to other locations or other species), it is highly likely that there are other contexts for which they hold. In common with most other regions, there is currently a very limited budget for restoration in the study area (approximately $\$ 400,000$ per year). Therefore it is important to invest these limited funds effectively, giving impetus to the use of the optimization approach presented here. Nevertheless, with this budget, the increase in abundance of woodland birds is predicted to be small (less than 2\%) even if resources are allocated optimally. Achieving more substantial outcomes is highly dependent on increasing the budget (see Tables 4 and 6 ). Accounting for private benefits in the optimization process would result in greater improvements in biodiversity outcomes than reported for the current study. However, in 
practice, a much larger budget would be needed if the abundance of woodland birds is to be maintained or improved in this highly cleared agricultural landscape.

\section{Acknowledgement}

This research was conducted with the support of funding from the Australian National Environmental Research Program's Environmental Decisions Hub and the Australian Research Council Centre of Excellence for Environmental Decisions. We thank Dr. Jim Radford and Bush Heritage Australia, who generously provided woodland bird survey data and Caroline Mitchell of the Centre for Environmental Economics and Policy for editorial help. Finally, we are grateful to two anonymous reviewers for their insightful comments. We take responsibility for any remaining omissions or errors. 


\section{References}

Adams, V.M., R.L. Pressey and N. Stoeckl. 2014. "Estimating Landholders' Probability of Participating in a Stewardship Program, and the Implications for Spatial Conservation Priorities." Plos One 9(6): e97941.

Ando, A., J. Camm, S. Polasky and A. Solow. 1998. "Species Distributions, Land Values, and Efficient Conservation.” Science 279(5359): 2126-2128.

Andren, H. 1994. "Effects of Habitat Fragmentation on Birds and Mammals in Landscapes with Different Proportions of Suitable Habitat: A Review." Oikos 71(3): 355-366.

Arponen, A., R.K. Heikkinen, C.D. Thomas and A. Moilanen. 2005. "The Value of Biodiversity in Reserve Selection: Representation, Species Weighting, and Benefit Functions." Conservation Biology 19(6): 2009-2014.

Australian National Biodiversity Strategy Review Task Group. 2010. Australia's Biodiversity Conservation Strategy 2010-2030 / Prepared by the National Biodiversity Strategy Review Task Group Convened under the Natural Resource Management Ministerial Council. Dept. of Sustainability, Environment, Water, Population and Communities, Canberra.

Australian State of the Environment Committee. 2006. Australia, State of the Environment 2006 : Independent Report to the Australian Government Minister for the Environment and Heritage / 2006 Australian State of the Environment Committee. Dept. of the Environment and Heritage, Canberra.

Babcock, B.A., P.G. Lakshminarayan, J. Wu and D. Zilberman. 1997. "Targeting Tools for the Purchase of Environmental Amenities." Land Economics 73(3): 325-339.

Bennett, A.F., J.Q. Radford and A. Haslem. 2006. "Properties of Land Mosaics: Implications for Nature Conservation in Agricultural Environments." Biological Conservation 133(2): 250-264.

Cabeza, M., M.B. Araujo, R.J. Wilson, C.D. Thomas, M.J.R. Cowley and A. Moilanen. 2004. “Combining Probabilities of Occurrence with Spatial Reserve Design.” Journal of Applied Ecology 41(2): 252-262.

Claassen, R., A. Cattaneo and R. Johansson. 2008. "Cost-Effective Design of AgriEnvironmental Payment Programs: U.S. Experience in Theory and Practice." Ecological Economics 65(4): 737-752.

Crossman, N.D. and B.A. Bryan. 2006. "Systematic Landscape Restoration Using Integer Programming." Biological Conservation 128(3): 369-383. 
Crossman, N.D. and B.A. Bryan. 2009. "Identifying Cost-Effective Hotspots for Restoring Natural Capital and Enhancing Landscape Multifunctionality." Ecological Economics 68(3): 654-668.

DSE. 2007. Overview of Native Vegetation Datasets, Information Sheet No. 1. Victorian

Government Department of Sustainability and Environment, Melbourne, Victoria, Australia.

DSE. 2012. Victorian Investment Framework for Natural Resource Management Statement of

Priorities 2012/2013. Department of Sustainability and Environment, Melbourne, Victoria, Australia.

DSE. 2013. Advisory List of Threatened Vertebrate Fauna in Victoria. Department of Sustainability and Environment, Melbourne, Australia.

Haslem, A. and A.F. Bennett. 2008. "Birds in Agricultural Mosaics: The Influence of Landscape Pattern and Countryside Heterogeneity." Ecological Applications 18(1): 185-196.

Lee, J.T. and S. Thompson. 2005. "Targeting Sites for Habitat Creation: An Investigation into Alternative Scenarios." Landscape and Urban Planning 71(1): 17-28.

Lewis, D.J., A.J. Plantinga and J.J. Wu. 2009. “Targeting Incentives to Reduce Habitat Fragmentation.” American Journal of Agricultural Economics 91(4): 1080-1096.

Lindenmayer, D.B., A.D. Manning, P.L. Smith, H.P. Possingham, J. Fischer, I. Oliver and M.A. McCarthy. 2002. “The Focal-Species Approach and Landscape Restoration: A Critique." Conservation Biology 16(2): 338-345.

Manning, A.D., J. Fischer and D.B. Lindenmayer. 2006. "Scattered Trees Are Keystone Structures - Implications for Conservation.” Biological Conservation 132(3): 311-321.

Margules, C.R. and R.L. Pressey. 2000. "Systematic Conservation Planning." Nature 405(6783): 243-253.

McBride, M.F., K.A. Wilson, J. Burger, Y.C. Fang, M. Lulow, D. Olson, M. O'Connell and H.P. Possingham. 2010. "Mathematical Problem Definition for Ecological Restoration Planning.” Ecological Modelling 221(19): 2243-2250.

Moilanen, A., A.M.A. Franco, R.I. Early, R. Fox, B. Wintle and C.D. Thomas. 2005. "Prioritizing Multiple-Use Landscapes for Conservation: Methods for Large MultiSpecies Planning Problems." Proceedings of the Royal Society B: Biological Sciences 272(1575): 1885-1891.

Morrison, M., E. Oczkowski and J. Greig. 2011. “The Primacy of Human Capital and Social Capital in Influencing Landholders' Participation in Programmes Designed to Improve 
Environmental Outcomes." Australian Journal of Agricultural and Resource Economics 55(4): 560-578.

Naidoo, R., A. Balmford, P.J. Ferraro, S. Polasky, T.H. Ricketts and M. Rouget. 2006. "Integrating Economic Costs into Conservation Planning." Trends in Ecology \& Evolution 21(12): 681-687.

Newburn, D., S. Reed, P. Berck and A. Merenlender. 2005. "Economics and Land-Use Change in Prioritizing Private Land Conservation." Conservation Biology 19(5): 1411-1420.

Ngugi, M.R., R.W. Johnson and W.J.F. McDonald. 2011. "Restoration of Ecosystems for Biodiversity and Carbon Sequestration: Simulating Growth Dynamics of Brigalow Vegetation Communities in Australia." Ecological Modelling 222(3): 785-794.

North Central Catchment Management Authority. 2005. North Central Native Vegetation Plan.

Olsen, P., M. Weston, C. Tzaros and A. Silcocks. 2005. The State of Australia's Birds 2005. Birds Australia, Melbourne.

Pannell, D.J. 2008. "Public Benefits, Private Benefits, and Policy Mechanism Choice for Land-Use Change for Environmental Benefits." Land Economics 84(2): 225-240.

Pannell, D.J. and A.M. Roberts. 2010. “Australia's National Action Plan for Salinity and Water Quality: A Retrospective Assessment.” Australian Journal of Agricultural and Resource Economics 54(4): 437-456.

Parkhurst, G.M., J.F. Shogren, C. Bastian, P. Kivi, J. Donner and R.B.W. Smith. 2002. "Agglomeration Bonus: An Incentive Mechanism to Reunite Fragmented Habitat for Biodiversity Conservation.” Ecological Economics 41(2): 305-328.

Peck, D.E. and R.M. Adams. 2010. "Farm-Level Impacts of Prolonged Drought: Is a Multiyear Event More Than the Sum of Its Parts." Australian Journal of Agricultural and Resource Economics 54(1): 43-60.

Polasky, S., J.D. Camm and B. Garber-Yonts. 2001. "Selecting Biological Reserves CostEffectively: An Application to Terrestrial Vertebrate Conservation in Oregon." Land Economics 77(1): 68-78.

Polasky, S., E. Nelson, J. Camm, B. Csuti, P. Fackler, E. Lonsdorf, C. Montgomery, D. White, J. Arthur, B. Garber-Yonts, R. Haight, J. Kagan, A. Starfield and C. Tobalske. 2008. "Where to Put Things? Spatial Land Management to Sustain Biodiversity and Economic Returns.” Biological Conservation 141(6): 1505-1524. 
Polasky, S., E. Nelson, E. Lonsdorf, P. Fackler and A. Starfield. 2005. "Conserving Species in a Working Landscape: Land Use with Biological and Economic Objectives." Ecological Applications 15(4): 1387-1401.

Polyakov, M., D.J. Pannell, R. Pandit, S. Tapsuwan and G. Park. 2013a. "Valuing Environmental Assets on Rural Lifestyle Properties." Agricultural and Resource Economics Review 42(1): 159-175.

Polyakov, M., D.J. Pannell, R. Pandit, S. Tapsuwan and G. Park. 2014. "Capitalized Amenity Value of Native Vegetation in a Multifunctional Rural Landscape." American Journal of Agricultural Economics (in press).

Polyakov, M., A.D. Rowles, J.Q. Radford, A.F. Bennett, G. Park, A. Roberts and D. Pannell. 2013b. "Using Habitat Extent and Composition to Predict the Occurrence of Woodland Birds in Fragmented Landscapes.” Landscape Ecology 28(2): 329-341.

Radford, J.Q. and A.F. Bennett. 2007. “The Relative Importance of Landscape Properties for Woodland Birds in Agricultural Environments." Journal of Applied Ecology 44(4): 737-747.

Radford, J.Q., A.F. Bennett and G.J. Cheers. 2005. "Landscape-Level Thresholds of Habitat Cover for Woodland-Dependent Birds.” Biological Conservation 124(3): 317-337.

Rashford, B.S. and R.M. Adams. 2007. "Improving the Cost-Effectiveness of Ecosystem Management: An Application to Waterfowl Production.” American Journal of Agricultural Economics 89(3): 755-768.

Rees, D.B. and J. Rowan. 2000. Land Systems of Victoria. Victoria Dept. of Natural, Resources and Environment, Centre for Land Protection and Research, Epsom, Vic.

Roberts, A.M., D.J. Pannell, G. Doole and O. Vigiak. 2012. “Agricultural Land Management Strategies to Reduce Phosphorus Loads in the Gippsland Lakes, Australia.” Agricultural Systems 106(1): 11-22.

Seavy, N.E. and J.D. Alexander. 2011. "Interactive Effects of Vegetation Structure and Composition Describe Bird Habitat Associations in Mixed Broadleaf-Conifer Forest.” Journal of Wildlife Management 75(2): 344-352.

Stoneham, G., V. Chaudhri, A. Ha and L. Strappazzon. 2003. "Auctions for Conservation Contracts: An Empirical Examination of Victoria's Bushtender Trial.” Australian Journal of Agricultural and Resource Economics 47(4): 477-500.

Thomson, J.R., A.J. Moilanen, P.A. Vesk, A.F. Bennett and R. Mac Nally. 2009. "Where and When to Revegetate: A Quantitative Method for Scheduling Landscape Reconstruction.” Ecological Applications 19(4): 817-828. 
Watts, M.E., I.R. Ball, R.S. Stewart, C.J. Klein, K. Wilson, C. Steinback, R. Lourival, L. Kircher and H.P. Possingham. 2009. "Marxan with Zones: Software for Optimal Conservation Based Land- and Sea-Use Zoning." Environmental Modelling and Software 24(12): 1513-1521.

Westphal, M.I., S.A. Field and H.P. Possingham. 2007. “Optimizing Landscape Configuration: A Case Study of Woodland Birds in the Mount Lofty Ranges, South Australia." Landscape and Urban Planning 81(1-2): 56-66.

Wilson, K.A., J. Carwardine and H.P. Possingham. 2009. Setting Conservation Priorities, pp 237-264.

Wilson, K.A., E.C. Underwood, S.A. Morrison, K.R. Klausmeyer, W.W. Murdoch, B. Reyers, G. Wardell-Johnson, P.A. Marquet, P.W. Rundel, M.F. McBride, R.L. Pressey, M. Bode, J.M. Hoekstra, S. Andelman, M. Looker, C. Rondinini, P. Kareiva, M.R. Shaw and H.P. Possingham. 2007. "Conserving Biodiversity Efficiently: What to Do, Where, and When." PLoS Biol 5(9): e223.

Wu, J., D. Zilberman and B.A. Babcock. 2001. "Environmental and Distributional Impacts of Conservation Targeting Strategies." Journal of Environmental Economics and Management 41(3): 333-350. 


\section{Tables}

Table 1. Areas of vegetation types in the study region.

\begin{tabular}{lcc}
\hline Groups of ecological & Current extent, ha & $\begin{array}{c}\text { Available for ecological } \\
\text { restoration, ha }\end{array}$ \\
vegetation types & & 50,231 \\
\hline Dry infertile woodlands & 53,035 & 120,281 \\
Fertile grassy woodlands & 22,730 & 49,451 \\
Plain woodlands & 2,700 & 13,413 \\
Riparian & 3,502 & 233,375 \\
\hline Total & 81,966 & \\
\hline
\end{tabular}


Table 2. Reduction in aggregate SPO when ecological restoration is optimized to maximize individual species SPO, relative to maximizing aggregate SPO

\begin{tabular}{lrr}
\hline Species & Reduction of aggregate SPO \\
\hline Black-chinned Honeyeater & 4826 & $6.9 \%$ \\
Brown-headed Honeyeater & 6861 & $9.8 \%$ \\
Buff-rumped Thornbill & 3444 & $4.9 \%$ \\
Brown Treecreeper & 10818 & $15.5 \%$ \\
Common Bronzewing & 6795 & $9.7 \%$ \\
Diamond Firetail & 5882 & $8.4 \%$ \\
Dusky Woodswallow & 4975 & $7.1 \%$ \\
Eastern Yellow Robin & 3468 & $5.0 \%$ \\
Fuscous Honeyeater & 9108 & $13.1 \%$ \\
Grey Fantail & 6077 & $8.7 \%$ \\
Grey Shrike-thrush & 9063 & $13.0 \%$ \\
Jacky Winter & 7350 & $10.5 \%$ \\
Mistletoebird & 3776 & $5.4 \%$ \\
Musk Lorikeet & 13305 & $19.1 \%$ \\
Purple-crowned Lorikeet & 12354 & $17.7 \%$ \\
Peaceful Dove & 8265 & $11.9 \%$ \\
Red-capped Robin & 5546 & $8.0 \%$ \\
Red Wattlebird & 16341 & $23.4 \%$ \\
Rufous Whistler & 7230 & $10.4 \%$ \\
Spotted Pardalote & 1249 & $1.8 \%$ \\
Varied Sittella & 7442 & $10.7 \%$ \\
White-browed Babbler & 3731 & $5.4 \%$ \\
Weebill & 6888 & $9.9 \%$ \\
White-naped Honeyeater & 7758 & $11.1 \%$ \\
White-throated Treecreeper & 11668 & $16.7 \%$ \\
White-winged Chough & 11220 & $16.1 \%$ \\
Yellow Thornbill & 14525 & $20.8 \%$ \\
Yellow-tufted Honeyeater & 6777 & $9.7 \%$ \\
\hline & & \\
& & \\
& & \\
& &
\end{tabular}


Table 3. SPO improvement and cost of optimal ecological restoration by maximizing aggregate SPO subject to different area of ecological restoration

\begin{tabular}{|c|c|c|c|c|}
\hline \multirow{2}{*}{$\begin{array}{c}\text { Area } \\
\text { constraint, ha }\end{array}$} & \multicolumn{3}{|c|}{ SPO improvement } & \multirow{2}{*}{$\begin{array}{c}\text { Cost, AU\$ } \\
\text { million }\end{array}$} \\
\hline & Direct effect & Indirect effect & Total & \\
\hline 1,000 & 2,595 & 2,965 & 5,560 & 6.7 \\
\hline 2,000 & 5,657 & 4,270 & 9,927 & 12.6 \\
\hline 4,000 & 12,252 & 6,487 & 18,739 & 23.5 \\
\hline 8,000 & 24,422 & 11,159 & 35,581 & 45.6 \\
\hline 16,000 & 49,204 & 18,652 & 67,856 & 88.0 \\
\hline
\end{tabular}


Table 4. SPO improvement of optimal ecological restoration by maximizing SPO subject to set of budget constraints

\begin{tabular}{|c|c|c|c|c|c|}
\hline \multirow{2}{*}{$\begin{array}{l}\text { Budget } \\
\text { constraint, } \\
\text { AU\$ } \\
\text { million }\end{array}$} & \multicolumn{3}{|c|}{ SPO improvement } & \multirow[b]{2}{*}{$\begin{array}{c}\text { Improvement } \\
\text { relatively to SPO } \\
\text { maximization } \\
\text { subject to area } \\
\text { constraint }\end{array}$} & \multirow[b]{2}{*}{$\begin{array}{c}\text { Similarity of } \\
\text { spatial patterns of } \\
\text { optimal solutions } \\
\text { subject to area } \\
\text { and cost } \\
\text { constraints }\end{array}$} \\
\hline & $\begin{array}{l}\text { Direct } \\
\text { effect }\end{array}$ & $\begin{array}{c}\text { Indirect } \\
\text { effect }\end{array}$ & Total & & \\
\hline 6.7 & 3,096 & 2,988 & 6,084 & $9.4 \%$ & $76 \%$ \\
\hline 12.6 & 6,402 & 4,292 & 10,694 & $7.7 \%$ & $80 \%$ \\
\hline 23.5 & 12,902 & 6,511 & 19,413 & $3.6 \%$ & $90 \%$ \\
\hline 45.6 & 25,668 & 11,203 & 36,871 & $3.6 \%$ & $90 \%$ \\
\hline 88.0 & 50,430 & 18,792 & 69,222 & $2.0 \%$ & $95 \%$ \\
\hline
\end{tabular}


Table 5. Extent of native vegetation, area available for ecological restoration, and optimal pattern of ecological restoration under under AU\$6.7 budget constraint by vegetation types.

\begin{tabular}{lcccc}
\hline \multirow{2}{*}{$\begin{array}{l}\text { Vegetation } \\
\text { types }\end{array}$} & $\begin{array}{c}\text { Available for } \\
\text { extent }\end{array}$ & $\begin{array}{c}\text { ecological } \\
\text { extent, }\end{array}$ & restoration, & Optimal ecological restoration \\
\cline { 4 - 5 } & ha & ha & ha & $\%$ of available \\
\hline Dry infertile & 53,035 & 50,231 & 145 & $0.29 \%$ \\
Fertile & 22,730 & 120,281 & 428 & $0.36 \%$ \\
Plain & 2,700 & 49,451 & 12 & $0.02 \%$ \\
Riparian & 3,502 & 13,413 & 533 & $3.97 \%$ \\
\hline Total & 81,966 & 233,375 & 1,118 & $0.48 \%$ \\
\hline
\end{tabular}


Table 6. SPO of targeted and non-targeted optimal ecological restoration under different budget constraints

\begin{tabular}{cccc}
\hline Budget, & \multicolumn{3}{c}{ SPO improvement by scenario: } \\
\cline { 2 - 4 } AU\$ million & Base case & LGA constraint & farm constraint \\
\hline 6.7 & 6,084 & 6,021 & 1,245 \\
12.6 & 10,694 & 10,778 & 3,158 \\
23.5 & 19,413 & 19,488 & 7,267 \\
45.6 & 36,871 & 36,925 & 16,926 \\
88.0 & 69,222 & 68,584 & 37,950 \\
\hline
\end{tabular}




\section{Figures}

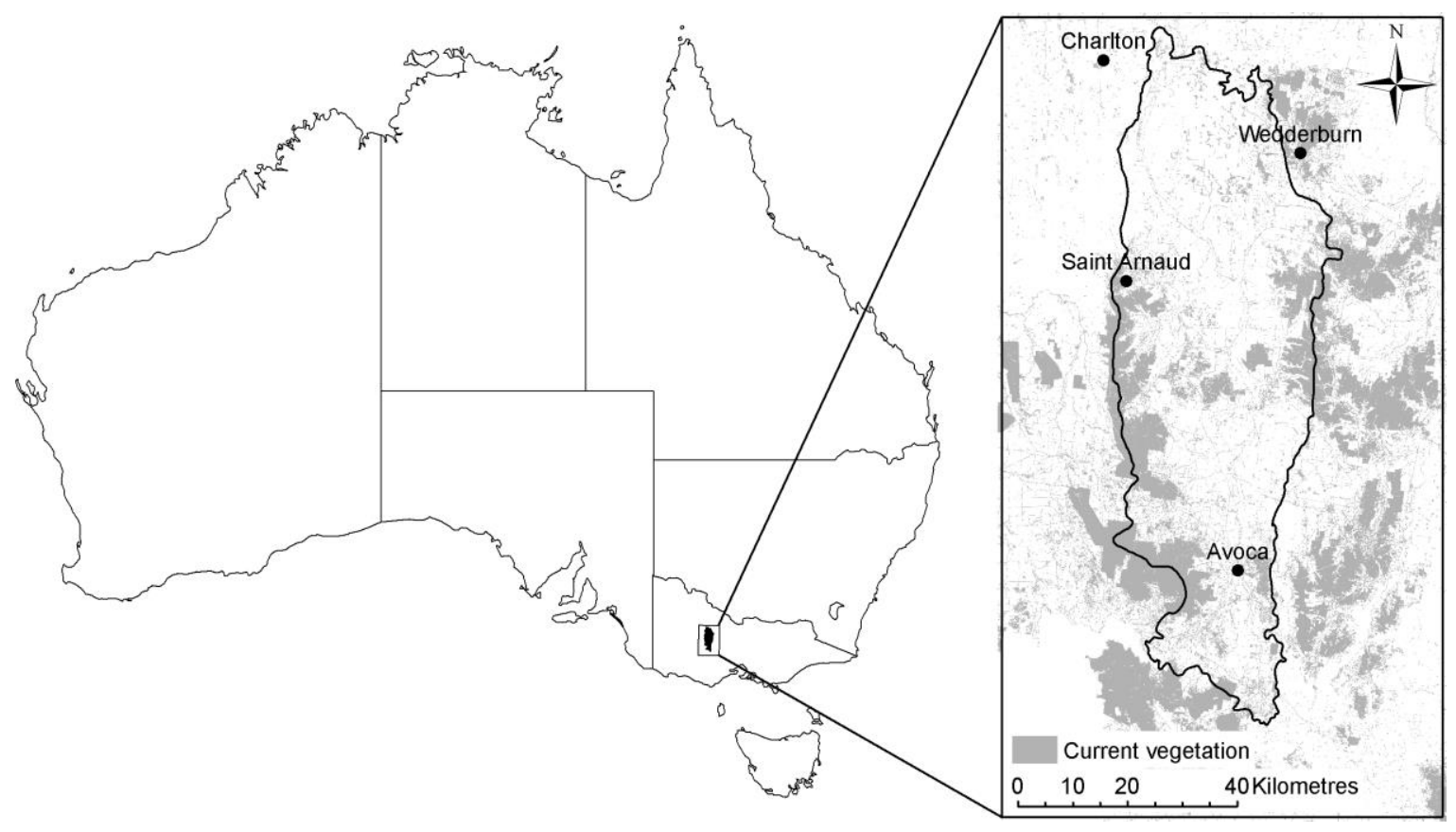

Figure 1. Avoca catchment study area 


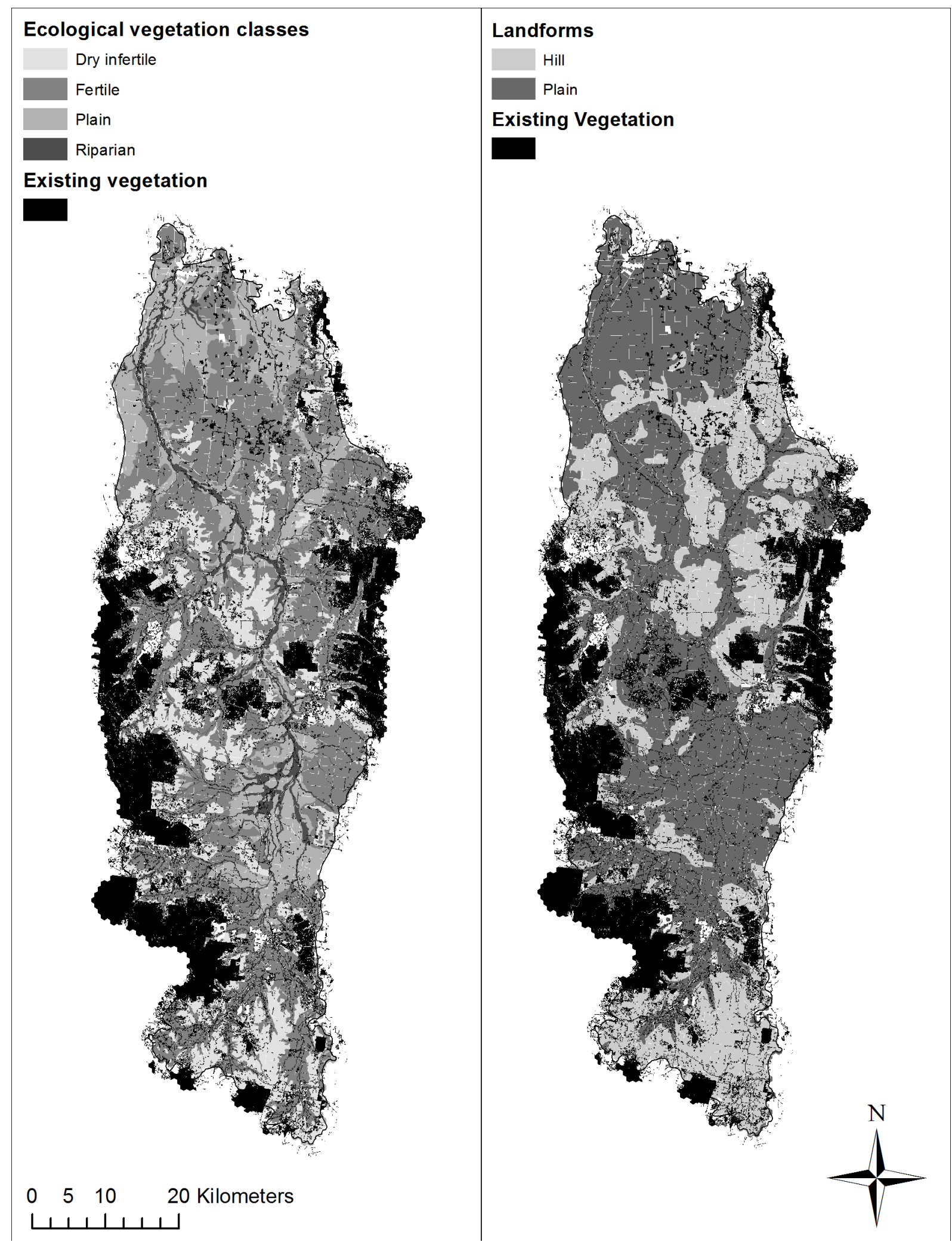

Figure 2. Spatial distribution of lands available for ecological restoration by vegetation type and landform 


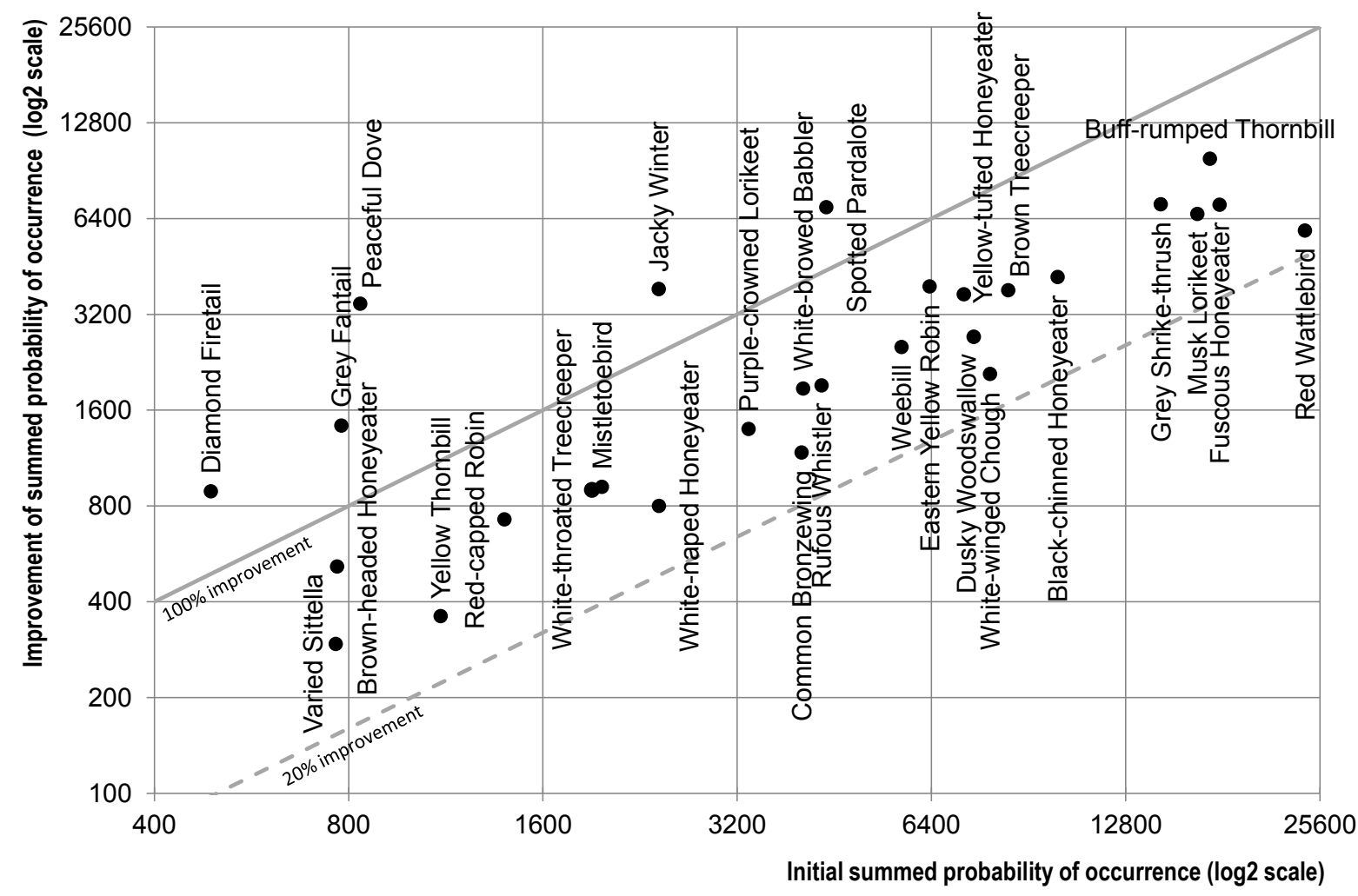

Figure 3. Response of individual bird species to optimal ecological restoration subject to area constraint equal to $20 \%$ of existing native vegetation 


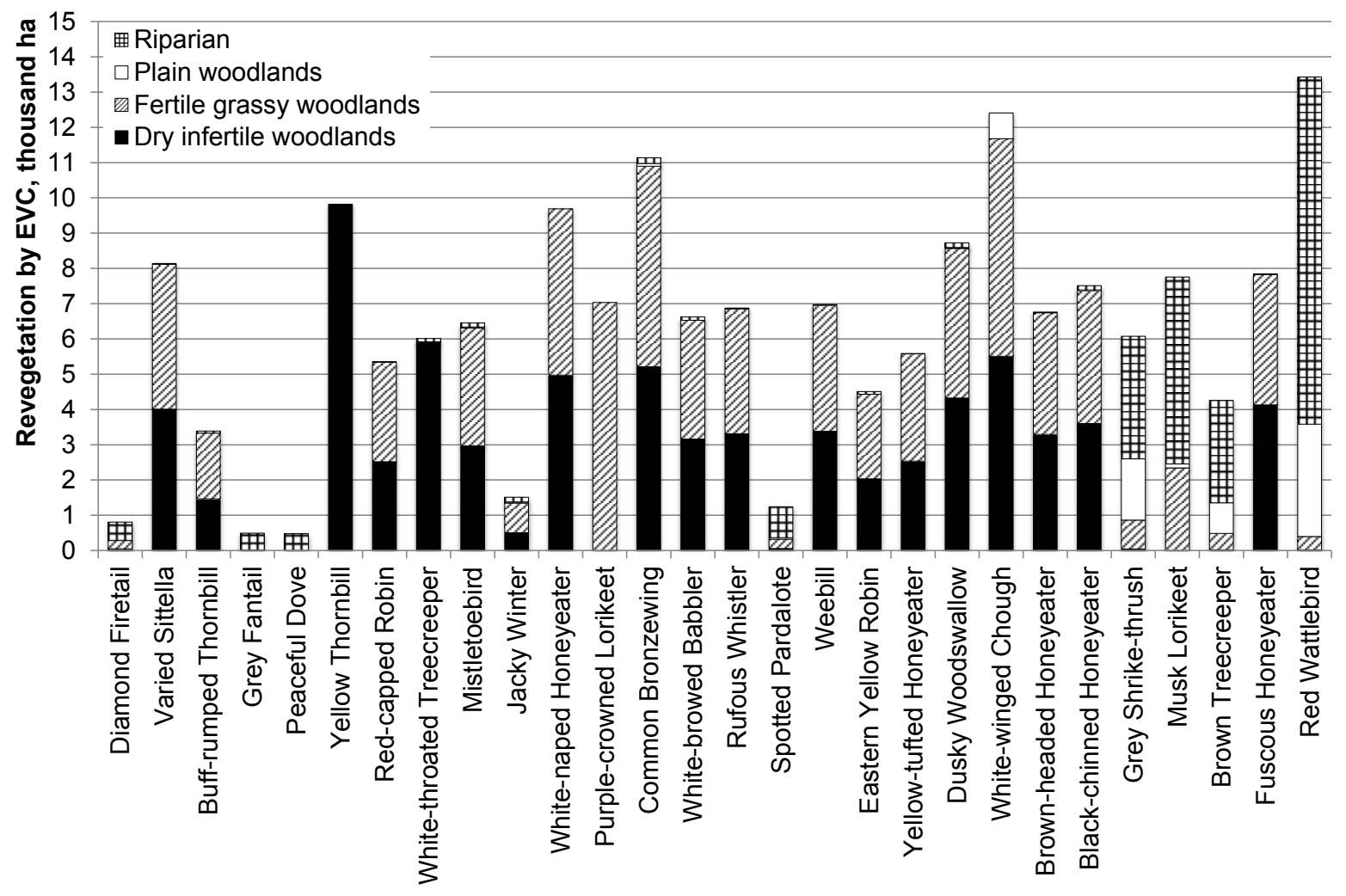

Figure 4. Area and Ecological Vegetation Classes of optimal ecological restoration to increase summed probability of occurrence of individual species by $20 \%$. The species are arranged from least abundant on the left to most abundant on the right 


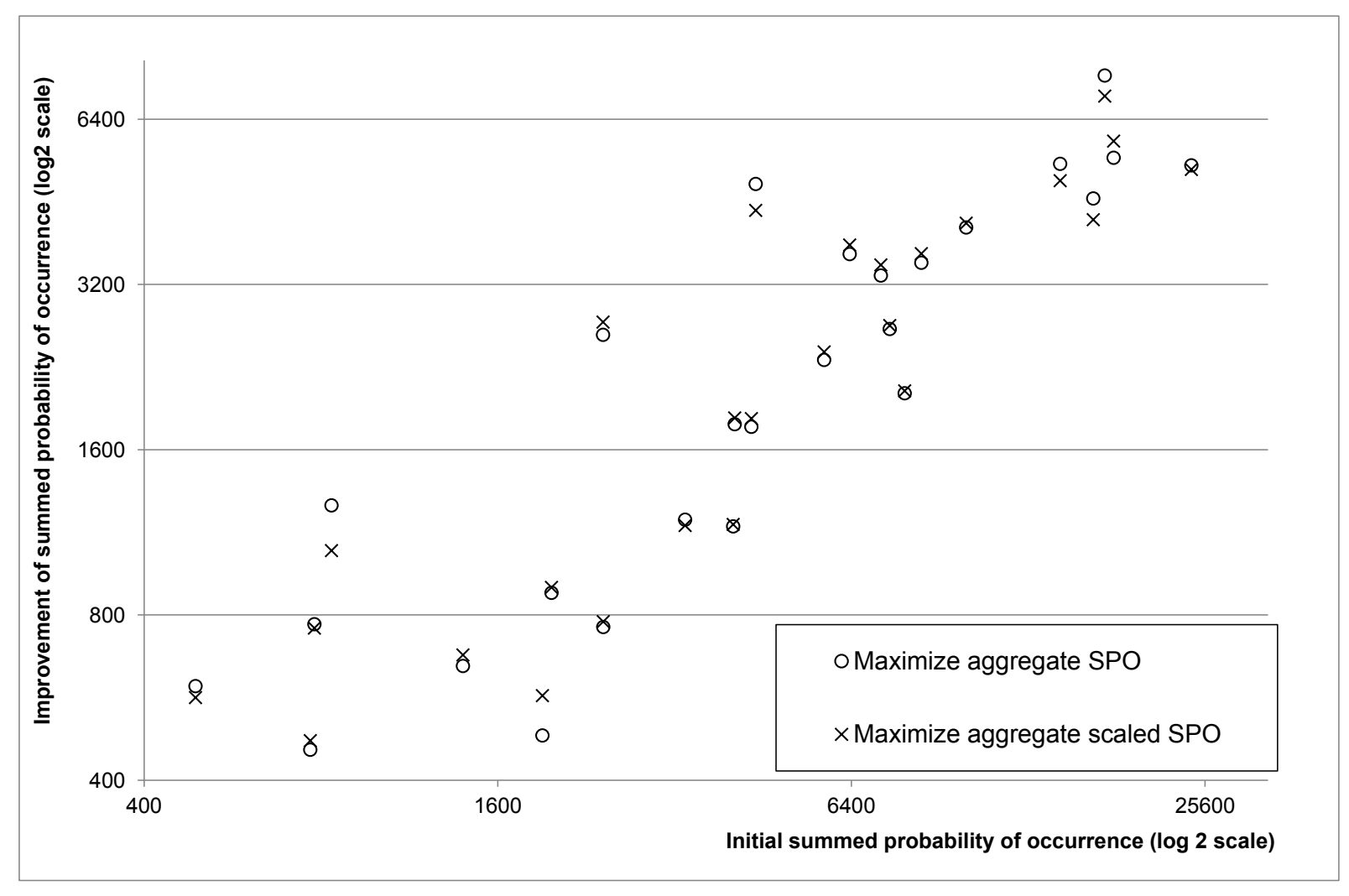

Figure 5. Response of individual bird species to optimal ecological restoration by maximizing aggregate SPO and maximizing aggregate weighted SPO and subject to area constraint equal to $20 \%$ of existing native vegetation 


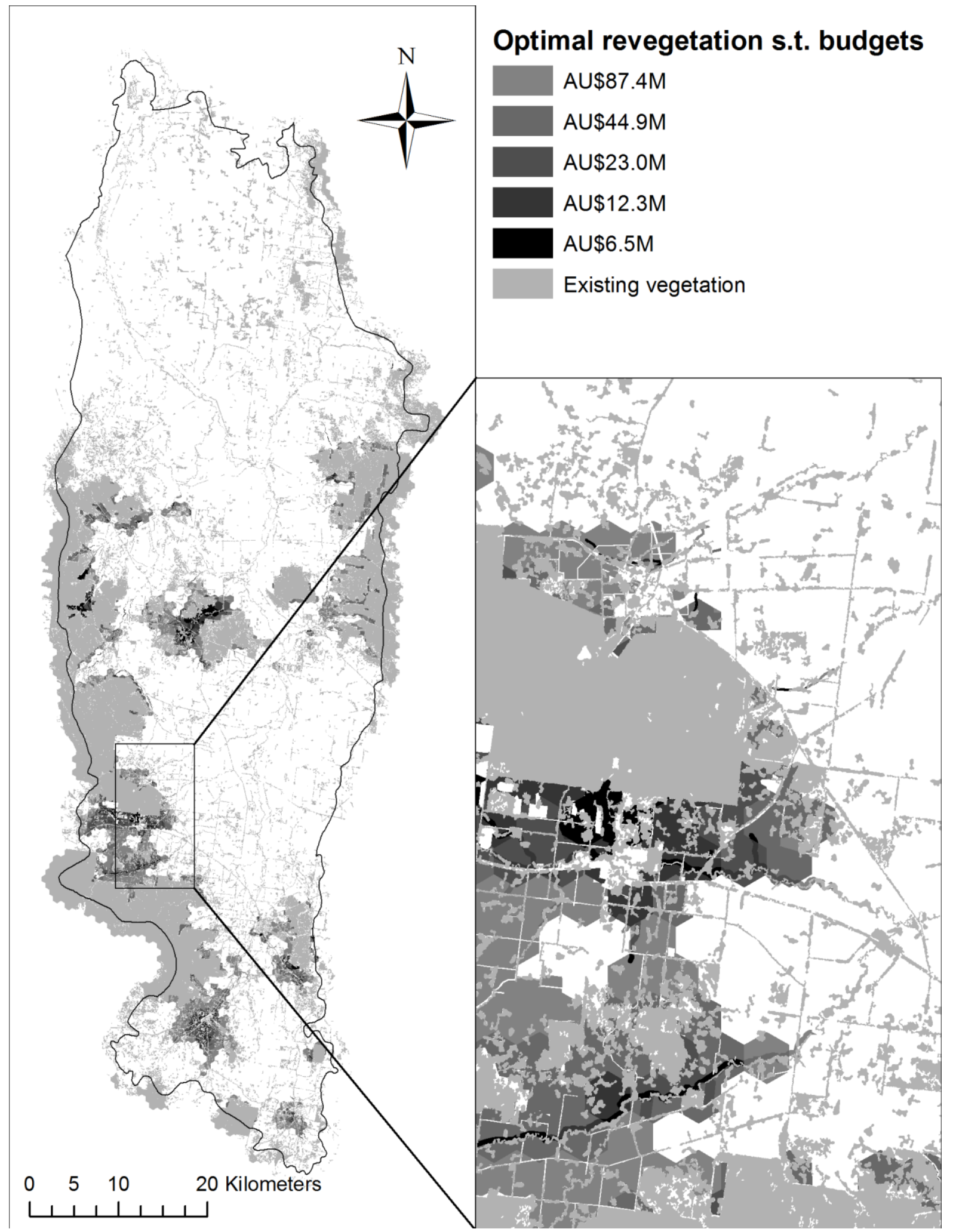

Figure 6. Spatial patterns of optimal ecological restoration in Avoca catchment subject to different budget constraints 


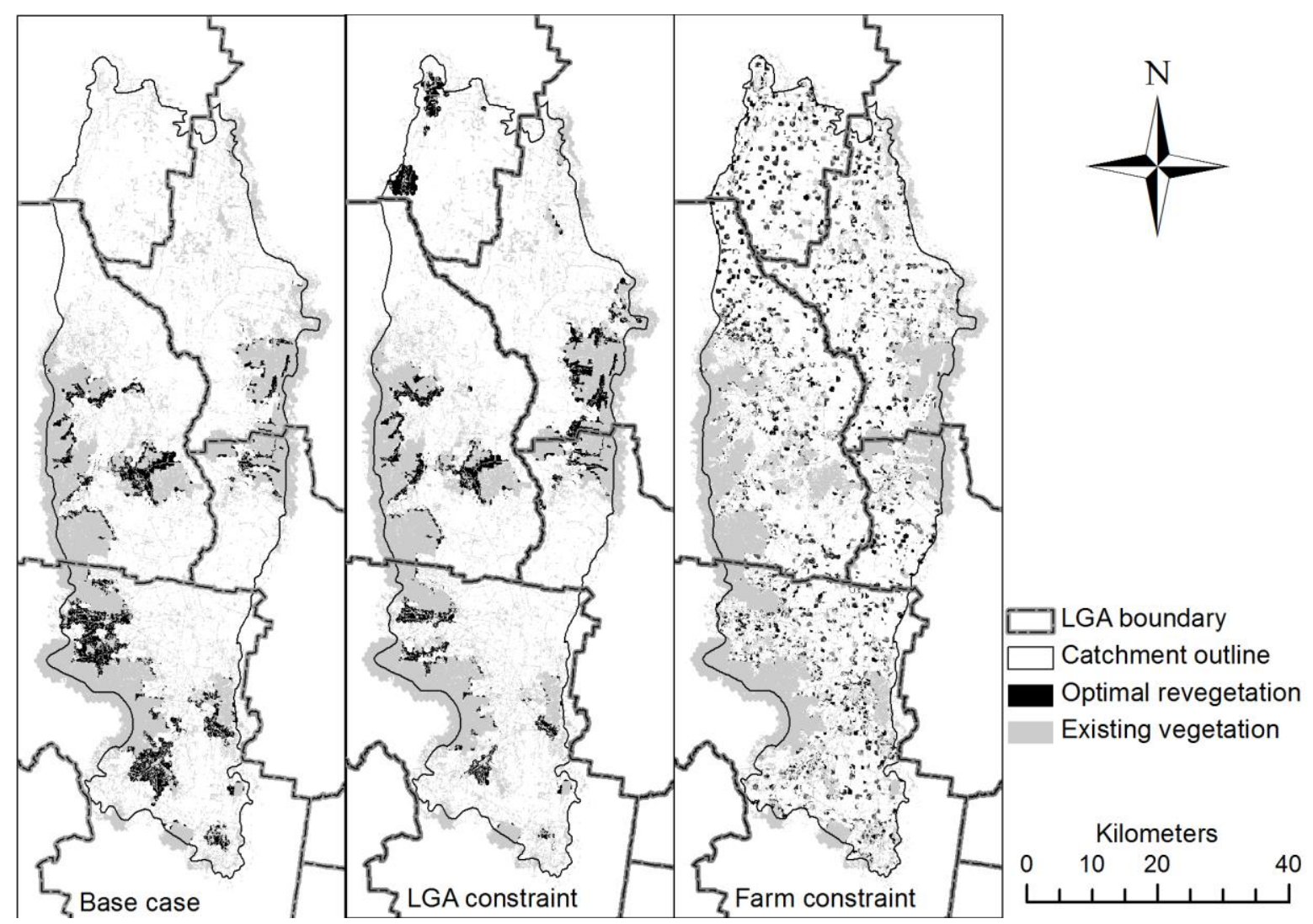

Figure 7. Spatial pattern of targeted and non-targeted ecological restoration in Avoca catchment under AU\$87.4M budget constraint 